\title{
Open Sandwich FRET Immunoassay of Estrogen Receptor $\beta$ in a PDMS Microfluidic Channel
}

\author{
Hyejin Park, Moonkwon Lee, Gi Hun Seong, Jaebum Choo, Eun Kyu Lee, ${ }^{\dagger}$ \\ Joong Yull Park, ${ }^{\ddagger}$ Sanghoon Lee, ${ }^{\ddagger}$ Kyeong-Hee Lee, ${ }^{\S}$ and Young-Wook Choi ${ }^{\text {s }}$ \\ Department of Applied Chemistry, Hampang Lniversity, Ansan 426-791, Korea. ${ }^{*}$-mail jbchooahanang ack kr \\ "Department of Chemical Engineering. Hanvang Lniversitv, Ansan $+26-791$, Korea \\ ${ }^{\star}$ Department of Biomedical Engineering, Korea Chiversity, Seoul 136-701, Korea \\ ${ }^{\$}$ Fision Technologv Research Laborator, KERI, Ansan $+26-170$, Korea \\ Received March 16, 2008
}

Key Words : FRET. Open sandwich immunoassay. Microfluidic channel. Estrogen receptor $\beta$

Inmunoassay is a fast and cost-effective protein detection method that can be applied to clinical diagnostics and biological research. Enzyme-linked immunosorbent assay (ELISA). surface plasmon resonance (SPR), and protein array chips are the most widely used immunoassay techniques for the detection of a target protein. ${ }^{1.2}$ In all of these methods. however. antibodies or antigens should be immobilized on a solid substrate. As a result. they require a long assay time for complete immunoreaction between antigens and antibodies being limited by the diffusion kinetics. Moreover. they also require several cycles of consecutive binding and washing steps to separate free reagents from binding reagents. To overcome the problem of slow immunoreactions in conventional immunoassay techniques. we recently reported a fast and sensitive one-step immunoassay of estrogen receptor $\beta(\mathrm{ER} \beta)$ using quantum dot (QD)-based fluorescence resonance energy transfer (FRET) ${ }^{3}$ To induce a strong FRET effect. QD was used as a fluorescence donor. FRET occurs when the electronic excitation energy of a donor chromophore is transferred to a nearby acceptor molecule via a dipole-dipole interaction between the donoracceptor pair. ${ }^{4.5}$ Conventional fluorescence dyes. which cause an appreciable overlap between the emission band of the donor and the absorption band of the acceptor. have generally been used as a donor-acceptor set. However. QD provides significant advantages over conventional fluorescence dyes. including brighter fluorescence. resistance to photobleaching. and narrow emission bands. which makes it suitable as a sensitive fluorescence donor. ${ }^{6-8}$ As a result. QD reaches a longer distance to the acceptor than conventional fluorescence dyes because of their superior optical properties. Furthermore. the QD-based FRET immunoassay of $\mathrm{ER} \beta$ was faster (30-40 min of immunoassay time including incubation) than conventional immunoassay techniques because it does not need any solid-phase carriers and multiple washing steps for free reagent separations. ${ }^{3}$ In our previous work the advantages of a QD-based FRET immunoassay in an open space were fully explored. Nonetheless. a faster reaction time and a smaller sample volume are still needed to apply this QD-based FRET immunoanalysis teclunique to clinical diagnostics.

In the present work a lab-on-a-chip technique combined with the QD-based FRET inmunoassay method. was used to develop a more sensitive and faster immunoanalysis technique. The lab-on-a-chip technique has several advantages over conventional bench-top tecluiques. such as minimal sample requirement. reduced reaction time. ease of use. improved product conversion, and reduced waste generation. $^{9-11}$ In particular, the reaction time can be greatly reduced to less than a few minutes if a properly designed channel to obtain highly efficient mixing is adopted. Furthermore, only a small reaction volume is required in the lab-ona-chip analysis. An alligator-teeth-shaped poly (dimethylsiloxane) (PDMS) microfluidic channel was fabricated to obtain a fast immunoreaction between antibody and antigen under a flow condition. The detailed fabrication process for this PDMS channel has been reported elsewhere. ${ }^{12-15}$

$\operatorname{ER} \beta$ is one of the most important breast cancer markers that are closely related with cell proliferations. ${ }^{\text {lit }}$ The antiER $\beta$ monoclonal antibody (McAb. mouse ascites. IgM isotype: Sigma. St. Louis. MO. USA) was labeled on QD 565 using an antibody conjugation kit (Invitrogen. Eugene. OR. USA). In addition, the anti-ER $\beta$ polyclonal antibody ( $\mathrm{PcAb}$. rabbit immune serum. IgG: Biogenex. San Ramon. CA. USA) was labeled with $\mathrm{AF} 568$ protein labeling kits (Invitrogen. Eugene, OR. USA). The fonnation of an open sandwich immunocomplex and its energy transfer process from QD-McAb to AF-PcAb are illustrated in Figure l(a).

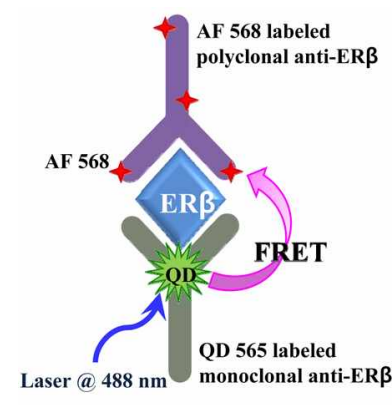

(a)

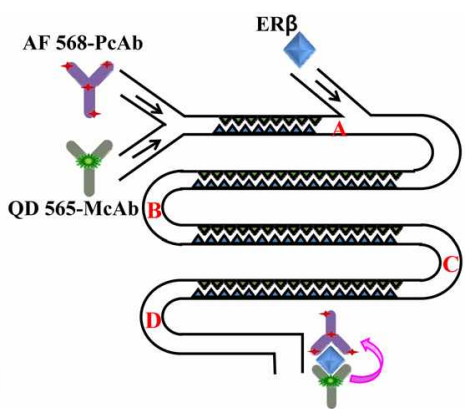

(b)
Figure 1. Schematic illustrations of (a) the FRET-based open sandwich immunoassay and (b) an alligator-teeth-shaped PDMS microtluidic channel for the FRET immunoassay. Each position (A to D) indicates a fluorescence measurement point. 

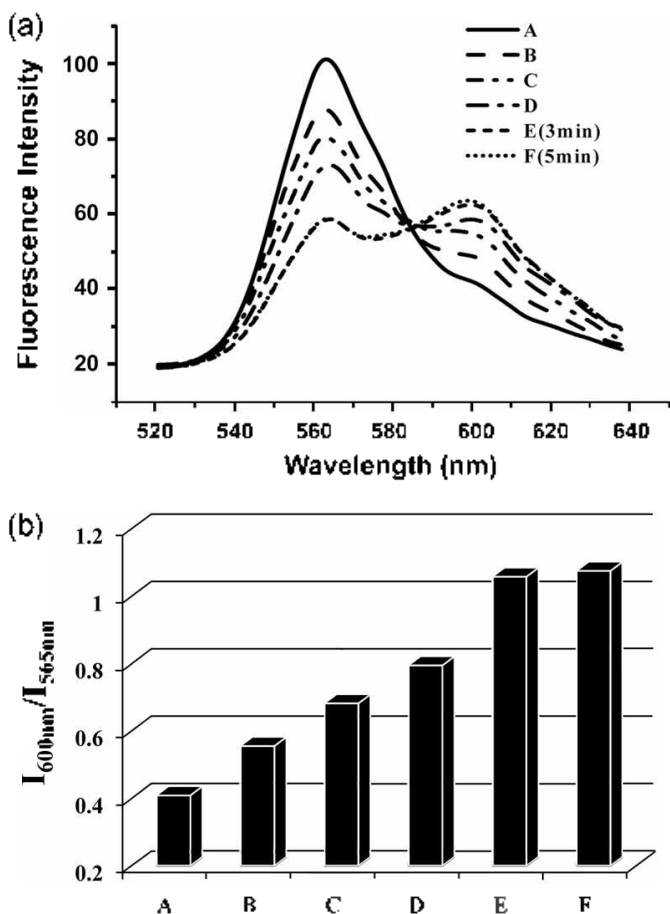

Figure 2. (a) Fluorescence emission spectra and (b) their relative fluorescence intensities measured at four difterent points along the channel with a constant flow rate of $2 \mu \mathrm{L} / \mathrm{min}$. Positions $\mathrm{A}, \mathrm{B}, \mathrm{C}$, and $D$ correspond to the fluorescence measurement points denoted in Figure 1 . E and $\mathrm{F}$ indicate the fluorescence spectra at position D after $3 \mathrm{~min}$ and $5 \mathrm{~min}$, respectively under stop-flow conditions

An on-chip assay process using a lab-on-a-chip device is shown in Figure 1(b). While confluent streams of QD$\mathrm{McAb}, \mathrm{AF}-\mathrm{PcAb}$. and antigen traveled along the nicrofluidic channel. the transverse and vertical dispersions of the fluid occurred sinultaneously through the upper and lower teeth. Fluorescence spectra in different channel positions were measured using a Leica TCS SP confocal fluorescence microscope. The QD 565 was excited by an Ar ion laser at $488 \mathrm{~mm}$. The emission band of QD 565 was observed in the $530-590 \mathrm{~nm}$ range. and the emission band of AF 568 was simultaneously observed in the 590-640 $\mathrm{nm}$ range. All the spectra during the sandwich immunobinding process of the $\mathrm{QD}-\mathrm{McAb}, \mathrm{AF}-\mathrm{PcAb}$, and $\mathrm{ER} \beta$ were measured using the $\lambda$ scanning mode of the confocal laser scanning microscope. The emitted fluorescent spectrum was detected in the 520$640 \mathrm{~nm}$ range.

Stock solutions of QD-McAb and AF-PcAb $(0.5 \mu \mathrm{M})$ were prepared in a PBS buffer solution $(\mathrm{pH}=7.2)$. $100 \mathrm{nM}$ $\mathrm{ER} \beta$ target antigen was also prepared for the FRET inmunoassay in a microfluidic device. Figure 2(a) shows the fluorescence spectra measured at four different positions (A, B C. and $D$ ) along the channel with a constant flow rate of $2 \mu \mathrm{L} /$ $\mathrm{min}$. The fluorescence bands at 565 and $600 \mathrm{~nm}$ correspond to the emission bands of QD 565 and AF 568. respectively. The intensity of QD 565 decreased with increasing channel distance. while the intensity of AF 568 increased. This means that the FRET between the donor QD 565 and the acceptor AF 568 successfully occurred as a result of the fonmation of the immunocomplex. The changes in the relative fluorescence intensity $\left(I_{600} / I_{565}\right)$ along the chamel distance for the formation of the sandwich immunocomplex are plotted in Figure 2(b). The continual increase of the relative intensity from $A$ to $D$ indicates that the immunoreaction has not been completed at channel position $D$ because the intensity still increases after channel position D. To find an equilibrium point for the completion of the immunoreaction, a stop-flow measurement was perfomed. The flow of the solution was stopped and the fluorescence signal was measured at intervals of $1 \mathrm{~min}$ at position D. According to our measurements, the relative fluorescence intensity remained constant after $3 \mathrm{~min}$.

In this work, a lab-on-a-chip-based FRET immunoassay technique for $\operatorname{ER} \beta$. which is known as one of the important breast cancer markers, was developed. This novel inmunoanalysis method requires only a tiny volume of sample (about $1.6 \mu \mathrm{L}$ ) because the inmunoreaction occurs in a narrow microfluidic channel. Furthermore. the analysis time is greatly reduced $(3.5 \mathrm{~min})$ compared with our previously reported results in open space $(30-40 \mathrm{~min})$ due to the high mixing efficiency of the alligator-teeth-shaped PDMS microfluidic channel. This conceptually new inmunoassay technique is considered to be a very effective diagnostic tool for specific cancer markers.

Acknowledgments. This work was supported by the research fund of Hanyang University (HY-2007-1).

\section{References}

1. Mullett. W. M.: Lai. E. P. C.: Yeung. J. M. Methods 2000. 22. 77.

2. Schuck. P. Amm Rev Biophus Bionol Stmict 1997. 26.541.

3. Wei, Q.: Lee, M.: Yu, X.; Lee. E. K: Seong. G. H.: Choo, J: Cho. Y. W. Anal Biochem 2006, 358, 31 .

4. Selvin. P. R. Kat. Struct. Biol. 2000. 7.730.

5. Clapp. A. R.: Medintz. I. L.: Mauro. I. M.: Fisher. B.: Bawendi. M. G. Mattoussi. H. J. Am. Chent. Soc. 2004. 126. 301.

6. Alivisatos. A. P. Science 1996. 27].933.

7. Mattoussi, H.: Medintz, I. L. Clapp. A. R: Goldman. E. R: Jaiswal, J. K.; Simon. S. M.: Mauro. J. M. J. Assoc. Lab. Alutom. 2004. 9.28 .

8. Kim. K.: Lee. S.: Lee. M.: Han. B.: Kim. S.: Choo. T: Shin. S. Y.: Lee. Y. H.: Gweon. D. G. Oh. C. H. Bull. Kon Chent. Sox. 2007. 28. 909.

9. Weigl. B. H.: Yager. P. Science 1999.283. 346.

10. Kenis, P. J. A.; Ismagilov. R. F.: Whitesides, G. M. Science 1999. 285.83

11. Heule. M.: Manz, A. Lab Chip 2004, 4. 506.

12. Park. 'l.: Lee. S.: Seong. G. H.: Choo. T.: Lee. E. K.: Kim. Y. S.: Ii. W. H.: Hwantg. S. Y: Gweon. D. G.: Lee. S. Lab Chip 2005. 5. 437.

13. Yea. K.: Lee. S.: Choo. T.: Oh. C. H.: Lee. S. Chent Conmmm. 2006. 1509 .

14. Jung J.; Choo, J.: Kim. D. J ; Lee. S. Bull. Kor Chem. Soc. 2006. 27. 277 .

15. Cher1. L.: Lee. S.: Lee. M.: Lim. C.: Choo. J.: Park. J. Y.: Lee. S.: Joo. S. W.: Lee. K. H.: Choi. Y. W. Biosents. Bioelectron. 2008. 23. 1878.

16. Palmieri, C.: Cheng. G. J:; Saji. S.; Zelada-Hedman. M.: Warri. A.; Weihua, Z; Van Noorden. S.; Wahlstrom. T.: Coombes, R. C: Warner, M.: Gustafsson, J. A. Endocr Relat. Cancer $\mathbf{2 0 0 2}$,9. 1. 